\title{
Pharmacokinetics of Modified Slow-Release Oral Testosterone Over 9 Days in Normal Men With Experimental Hypogonadism
}

\author{
Ada Lee ${ }^{\star}$, Katya Rubinow ${ }^{\star}$, Richard V. Clark ${ }^{\dagger}$, Ralph B. Caricofe ${ }^{\dagger}$, Mark A. Bush $^{\dagger}$, Hui Zhi ${ }^{\dagger}$, \\ Mara Y Roth ${ }^{*}$, Stephanie T. Page ${ }^{*}$, William J. Bremner ${ }^{*}$, and John K. Amory \\ ${ }^{*}$ Center for Research in Reproduction and Contraception, Divisions of General Internal Medicine \\ and Metabolism, Endocrinology and Nutrition, Department of Medicine, University of Washington \\ Medical School, Seattle, Washington \\ †GlaxoSmithKline Research and Development, Research Triangle Park, North Carolina
}

\section{Abstract}

\begin{abstract}
Oral administration of testosterone has potential use for the treatment of hypogonadism. We have recently demonstrated that a novel formulation of oral testosterone transiently normalized serum testosterone in a single-dose pharmacokinetic study. In this report, we present the steady-state pharmacokinetics of this formulation. Twelve healthy young men were rendered hypogonadal with the gonadotropin-releasing hormone antagonist acyline (300 $\mu \mathrm{g} / \mathrm{kg}$ subcutaneously) and administered $300 \mathrm{mg}$ of oral testosterone 3 times daily for 9 days. Serum testosterone, dihydrotestosterone (DHT), estradiol, and sex hormone-binding globulin (SHBG) were measured before and 1, 2, 4, 5, 6, 8, 10,11,12, 14, 16, and 24 hours on the first and ninth day of dosing. Before testosterone administration, all men had serum testosterone under $75 \mathrm{ng} / \mathrm{dL}$. Over day 1 , the 24-hour average (geometric mean [\% CV]) serum total testosterone was $378(45) \mathrm{ng} / \mathrm{dL}$. This decreased to 315 (41) ng/dL after 9 days of continuous treatment $(P=.1$ compared with day 1$)$. The 24-hour average serum SHBG was $27(46) \mathrm{nmol} / \mathrm{L}$ on day 1 and was significantly reduced to $19(47) \mathrm{nmol} / \mathrm{L}$ by day $9(P>.01)$. As a result, the calculated free testosterone values were similar between day 1 and day 9: 8.7 (43) and 8.3 (37) ng/dL, respectively. DHT was in the reference range and estradiol was slightly below on day 9 . Oral testosterone $(300 \mathrm{mg})$ dosed 3 times daily normalized serum testosterone in men with experimentally induced hypogonadism after 9 days of dosing and significantly suppressed SHBG. This formulation of oral testosterone may have efficacy for the treatment of testosterone deficiency.
\end{abstract}

\section{Keywords}

Androgen; drug delivery; dihydrotestosterone; DHT; estradiol; acyline

\begin{abstract}
Testosterone is the most important sex steroid in men because it plays an essential role in many aspects of male health. Approximately 5\% of men have low serum testosterone and signs or symptoms of hypogonadism, including: reduced libido, erectile dysfunction,
\end{abstract}

Copyright $@$ American Society of Andrology

Correspondence to: John K. Amory, University of Washington, Box 356429, 1959 NE Pacific St, Seattle, WA 98195 (jamory@u.washington.edu). 
osteoporosis, or diminished physical performance (Araujo et al, 2007). Men with hypogonadism benefit from testosterone replacement, which increases bone and muscle mass and maintains sexual and physical functioning (Katznelson et al, 1996; Wang et al, 1996; Snyder et al, 2000).

In the United States, recommended forms of testosterone therapy include intramuscular injections, transdermal patches and gels, subdermal pellets, and buccal tablets; oral testosterone undecanoate is available in many other countries. Oral alkylated testosterone derivatives (eg, methyltestosterone and oxandrolone) are also available. Unfortunately, these formulations of oral testosterone, all of which are alkylated at the 17-carbon position, are associated with liver toxicity in a substantial proportion of long-term users (Westaby et al, 1977; Turani et al, 1983; Lowdell and Murray-Lyon, 1985; Pavlatos et al, 2001). As a result, these alkylated oral androgens are generally not considered safe for the long-term treatment of male hypogonadism.

The recommended formulations of testosterone have drawbacks as well. Testosterone injections must be given intramuscularly every 1-3 weeks and can be painful (Fossa et al, 1999). Testosterone patches cause skin reactions in more than one-half of patients using them (Dobs et al, 1999). Testosterone gels are safe and effective but show variable absorption (Wang et al, 2000) and are expensive. Additionally, gels carry the risk of inadvertently exposing women and children to testosterone (Brachet et al, 2005; de Ronde, 2009), a finding which has recently resulted in a "black box" warning regarding their use from the US Food and Drug Administration (2009). For these reasons, as well as for ease of dosing, oral administration of testosterone might be preferable to currently available options.

Oral administration of nonalkylated testosterone was previously thought to be ineffective because of rapid hepatic metabolism (Foss, 1939; Daggett et al, 1978). Nevertheless, we have reported that when nonalkylated testosterone is administered orally at a sufficient dose, serum testosterone concentrations within the reference range can be achieved without acute adverse effects on liver function (Amory and Bremner, 2005; Amory et al, 2006). More recently, we have shown that oral administration of a novel modified slow-release formulation of oral testosterone has excellent pharmacokinetics (Snyder et al, 2010). Compared with our previous "immediate-release" formulation of oral testosterone (Page et al, 2008), modified slow-release oral testosterone exhibits significantly lower maximum concentrations of testosterone and a delayed time of maximum serum testosterone in a single-dose pharmacokinetic study. Importantly, with this formulation, the serum testosterone concentration stayed above the lower limit of the reference range for longer than 8 hours, which was longer than was observed with the other formulations. Therefore, this formulation was chosen for a multidose pharmacokinetic study to determine if it would be suitable for long-term use in hypogonadal men. We hypothesized that a dose of $300 \mathrm{mg}$ of modified slow-release oral testosterone 3 times daily would normalize serum testosterone after 9 days of use. We tested this hypothesis in a group of 12 normal men with experimentally induced hypogonadism. 


\section{Materials and Methods}

\section{Subjects}

Twelve men, 18-55 years of age, in good health, were recruited through local newspapers and campus flyers. After informed consent was obtained, subjects underwent screening procedures consisting of a medical history, a physical examination, measurements of serum hormone levels, and routine laboratory tests, including complete blood counts, serum chemistries, liver function tests, and measurement of prostate-specific antigen (PSA). Specific exclusion criteria included current use of testosterone, infertility, poor general health, clinically significant abnormal laboratory results, history of testicular disease or severe testicular trauma, a PSA of more than 4.0, major psychiatric disorders, use of illicit drugs or the use of more than 3 alcoholic beverages daily, participation in a hormonal drug study within the last month, a history of bleeding disorders or the use of anticoagulants, or the use of medications known to interfere with testosterone synthesis, action, or metabolism.

\section{Study Design}

We conducted an open-label, 9-day, pharmacokinetic study of modified slow-release oral testosterone dosed at $300 \mathrm{mg} 3$ times daily. To ensure normal metabolism of testosterone, we conducted this study in normal men whose endogenous testosterone production was temporarily suppressed by the subcutaneous administration of $300 \mathrm{mg} / \mathrm{kg}$ of acyline, a potent GnRH antagonist that suppresses endogenous testosterone production in men for 1014 days (Herbst et al, 2004).

The modified slow-release oral testosterone was prepared by GlaxoSmithKline (Research Triangle Park, North Carolina), with each tablet containing $300 \mathrm{mg}$ of testosterone in a proprietary matrix of excipients. Acyline was obtained from NeoMPS (San Diego, California). Twenty-four hours after administration of acyline, subjects were admitted to the General Clinical Research Center at the University of Washington for 24 hours. During this visit (day 1), subjects were administered $300 \mathrm{mg}$ of modified slow-release oral testosterone at $t=0$ hours, 4 hours, and 10 hours with normal meals without a prespecified fat content. These dosing times were chosen to correspond with meals as a more "real world" approach to dosing the testosterone. Subjects had blood drawn before dosing and 1, 2, 4, 5, 6, 8, 10, $11,12,14,16$, and 24 hours after the first dose on day 1 for the measurement of serum testosterone, dihydrotestosterone (DHT), sex hormone-binding globulin (SHBG), and estradiol. After discharge, subjects then self-administered $300 \mathrm{mg}$ modified slow-release oral testosterone 3 times daily for 7 days at mealtimes before readmission to the Clinical Research Center (day 9). On day 9, subjects repeated the 24-hour blood sampling procedures and testosterone dosing exactly as performed on day 1 . For safety monitoring, subjects had blood counts, serum chemistries, and liver function tests measured on days 2, 4, and 10 after the last dose of testosterone. At each study visit, study personnel queried subjects regarding adverse events. Any complaint was documented in the study chart. Subjects were asked to not drink more than 3 alcoholic beverages daily during the study. Study subjects were paid $\$ 900$ for their participation in the study The University of Washington Investigational Review Board approved all aspects of this study before study initiation, and signed consent 
on an approved consent form was obtained before the performance of any study procedures. This study was registered in advance at clinicaltrials.gov as study NCT01167829.

\section{Measurements}

Serum total testosterone, DHT, and estradiol were measured by a validated gas chromatography/tandem mass spectrometry assay at a central laboratory as described previously (Page et al, 2008). The interassay coefficient of variation for low, mid, and high concentrations of testosterone were $5.4 \%, 4.5 \%$, and $1.2 \%$, respectively, and for DHT were $6.3 \%, 6.3 \%$, and $3.3 \%$, respectively. Intra-assay coefficients of variation for low, mid, and high concentrations of testosterone were $3.7 \%, 4.1 \%$, and $0.8 \%$, respectively, and for DHT were $1.4 \%, 3.4 \%$, and $5.1 \%$, respectively. The lower limits of detection for testosterone and DHT were $50.0 \mathrm{pg} / \mathrm{mL}$ and $10.0 \mathrm{pg} / \mathrm{mL}$, respectively. Free testosterone was calculated using the Vermeulen formula (Vermeulen et al, 1999). SHBG was measured by radioimmunoassay (Delfia, Perkin-Elmer, Waltham, Massachusetts) with intra-and interassay coefficients of variation of $6.0 \%$ and $9.1 \%$, respectively, on midrange pools of serum.

The reference ranges for these hormones and SHBG were: total testosterone (300-1000 ng/ $\mathrm{dL}$ ), free testosterone (4.7- $18 \mathrm{ng} / \mathrm{dL})$, DHT (30-90 ng/dL), estradiol (10-60 pg/mL), and SHBG (3-57 nmol/L). Blood counts, serum chemistries, and liver function tests were measured by the University of Washington Hospital clinical laboratory.

\section{Statistical Analysis}

Means and standard errors were calculated for hormone concentrations at each time point. The pharmacokinetic parameters are presented as geometric means and coefficients of variation $(\mathrm{CV})$. For the pharmacokinetic analyses, maximum concentration after dosing and 24-hour time-averaged concentrations were calculated for each subject with the use of WinNonLin (PharSight, Sunnyvale, California) and the formula Cavg $=\operatorname{AUC}(0-24$ h)/24. For statistical testing, paired $t$ tests were performed on log-transformed data. The proportion of 24-hour-averaged hormone concentrations in the reference range between day 1 and day 9 was compared using Fisher's exact test. Statistical analyses were performed using STATA version 10 (College Park, Texas). For all comparisons, an alpha of 0.05 was considered significant.

\section{Results Subjects}

Fourteen subjects were screened for study participation. Two were excluded, 1 for stage II hypertension and the other for pre-existing peripheral arterial disease. A total of 12 subjects were enrolled and completed all study-related visits and procedures. The baseline subject characteristics for the subjects are shown in Table 1.

There were no serious adverse events. Eight nonserious adverse events occurred in 6 study subjects. Two patients had minor musculoskeletal injuries with clear precipitants, and 2 patients experienced mild upper respiratory infections. One subject reported a transient 
episode of confusion likely due to heat exposure that occurred 2 weeks after the 9-day drug exposure period, but this resolved completely without sequelae before his follow-up visit. One subject reported a headache, and 1 subject experienced mild to moderate symptoms of hypogonadism including low libido and irritability after the 9-day drug exposure period, but before the follow-up visit. These symptoms resolved spontaneously, and his serum hormone concentrations were normal at the follow-up visit. Furthermore, there were no adverse gastrointestinal symptoms associated with the oral testosterone formulation.

One subject demonstrated a transient elevation in serum aspartate aminotransferase, alanine aminotransferase, and serum bilirubin on treatment day 4 , but the peak values of these measures did not exceed the prespecified stopping criterion of 3 times the upper limit of normal. These elevations were temporally associated with an episode of drinking greater than 6 alcoholic beverages and resolved completely by day 9 despite continued administration of oral testosterone per protocol. Excepting the symptoms of hypogonadism in 1 subject, none of the adverse events were judged to be study-related, and none required study withdrawal.

\section{Serum Hormone Pharmacokinetics}

Twenty-four hours after acyline administration and immediately before the first dose of oral testosterone, serum total testosterone levels in all subjects were markedly suppressed to an average of $62 \pm 14 \mathrm{ng} / \mathrm{dL}$. On day 1,1 hour after the administration of $300 \mathrm{mg}$ of modifiedrelease oral testosterone, the mean serum testosterone $( \pm$ SEM) was $633 \pm 90 \mathrm{ng} / \mathrm{dL}$. Mean serum testosterone remained within the reference range throughout the first 16 hours of day 1 but was close to predose baseline by 24 hours after the morning dose of testosterone (the Figure [A]). Similarly, on day 9, the mean serum testosterone remained within the reference range for 14 hours after the morning dose of testosterone. On day 1, the 24-hour average total testosterone (geometric mean [\%CV]) was 378 (45) ng/dL. On day 9, the 24-hour average total testosterone was $315(41) \mathrm{ng} / \mathrm{dL}$, which is at the lower end of the reference range ( $P=.1$ compared with day 1 ; Table 2 ). The proportion of subjects with a 24-hour average total testosterone in the reference range on day 1 was $75 \%(9 / 12)$ and $58 \%(7 / 12)$ on day $9(P=.3)$. Five of the $12 \mathrm{men}$ had a 24 -hour average total testosterone below the lower limit of the reference range on day 9; none had a 24-hour total testosterone above the upper limit of the reference range. The geometric mean $(\% \mathrm{CV})$ maximum serum testosterone on days 1 and 9 were 924 (44) ng/dL and 741 (71) ng/dL ( $P=.03$ compared with day 1), respectively. Only 1 subject had a maximum testosterone greater than 2 times the upper limit of the reference range.

DHT concentrations were elevated above the reference range on much of day 1, but only in the morning on day 9 (Figure [B]). On day 1, the 24-hour average geometric mean (\%CV) serum DHT was slightly above the reference range, 96 (38) $\mathrm{ng} / \mathrm{dL}$, but within the reference range on day 9, 69 (41) $\mathrm{ng} / \mathrm{dL}$ ( $P=.02$ compared with day 1 ; Table 2 ). The proportion of subjects with a 24-hour average DHT in the reference range on day 1 was 50\% (6/12) and $83 \%(10 / 12)$ on day $9(P=.19)$. The geometric mean $(\% \mathrm{CV})$ maximum concentration for serum DHT on day 1 was $233(49) \mathrm{ng} / \mathrm{dL}$ and $142(55) \mathrm{ng} / \mathrm{dL}$ on day 9 ( $P=.01$ compared with day 1). 
On day 1 , mean serum estradiol concentrations were slightly above the lower limit of the reference range, but by day 9 , the mean serum estradiol concentrations were below the lower limit of the reference range (Figure [C]). On day 1, the geometric mean (\%CV) 24-hour average serum estradiol was $11(18) \mathrm{pg} / \mathrm{mL}$, and on day 9 , the 24-hour average estradiol was $7(18) \mathrm{pg} / \mathrm{mL}(P>.01$ compared with day 1$)$.

On day 1, the geometric mean (\%CV) of 24-hour average serum SHBG was $27(46) \mathrm{nmol} / \mathrm{L}$, but this decreased significantly by day 9 to $19(47) \mathrm{nmol} / \mathrm{L}$ ( $P>.01$ compared with day 1$)$. Because of this reduction in SHBG, calculated free testosterone levels were very similar between day 1 and day 9 (Figure [D]), with the geometric mean (\%CV) 24-hour average free testosterone of $8.7(43) \mathrm{ng} / \mathrm{dL}$ on day 1 and $8.3(37) \mathrm{ng} / \mathrm{dL}$ on day $9(P=.55)$.

\section{Discussion}

In this report, we present the multidose pharmacokinetics of 9 days of a novel modified slow-release formulation of oral testosterone in men with experimentally induced hypogonadism. In this study, thrice daily administration of this formulation of oral testosterone normalized the 24-hour average serum testosterone concentrations with resulting peak serum testosterone concentrations less than 2 times the upper limit of the reference range in all but a single subject on day 9. Interestingly, the mean serum concentrations of total testosterone decreased between day 1 and day 9 , likely because of the significant reduction in serum SHBG between these time points. This roughly $25 \%$ reduction in serum SHBG is not observed with transdermal route testosterone administration (Winters and Wang, 2010) but has been described after injection of intramuscular testosterone (Zhang et al, 1998). As a result of the reduction in serum SHBG, the calculated free testosterone concentrations on day 1 and day 9 were very similar, and all subjects had a 24-hour average free testosterone in the reference range on day 9. Additionally, this dose of oral testosterone results in 24-hour serum total testosterone and DHT concentrations within the reference range in a majority of subjects after 9 days of use.

On day 1, serum DHT concentrations were noted to be elevated above the reference range; however, both average levels and peak concentrations of DHT decreased significantly over the treatment period of 9 days. Significant elevations in serum DHT are also observed with treatment with oral testosterone undecanoate (Nieshlag et al, 1975; Frachmont et al, 1978; Roth et al, 2011). Other forms of testosterone therapy, such as patches and gels, are also associated with increased concentrations of DHT, presumably because of the presence of 5areductase in the skin (Swerdloff et al, 2000). In terms of testosterone therapy, such increases might increase the risk of DHT-related conditions such as acne, benign prostatic hypertrophy, and androgenic alopecia, although the magnitude of any risk is unknown because it is unclear whether circulating concentrations of DHT correlate with an increased risk of these conditions. A case in point is the poorly understood and controversial relationship between serum DHT and the risk of prostate cancer. On one hand, the increased serum DHT concentrations resulting from therapy with oral testosterone undecanoate (Gooren, 1994) or with chronic administration of a DHT gel (Idan et al, 2010) do not seem to be associated with an increased risk of prostate cancer or prostate enlargement. This may be because intraprostatic concentrations of DHT do not change even after circulating serum 
DHT are markedly increased by the administration of a DHT gel (Page et al, 2011).

Additionally, most epidemiological studies do not find an association between serum DHT and the risk of prostate cancer (Gann et al, 1996; Gill et al, 2010). On the other hand, 2 large, prospective, placebo-controlled trials have demonstrated that the administration of either finasteride or dutasteride reduces the risk of prostate cancer by approximately $25 \%$ (Thompson et al, 2003; Andriole et al, 2010). However, both of these studies raised the concern that the reduction in serum DHT might actually increase the risk of prostate cancers with higher Gleason scores that are associated with significantly more aggressive tumors. Clearly, a greater understanding of the association between DHT, prostate cancer, and other DHT-related conditions is required.

Serum total estradiol remained within the reference range during the entire treatment period on day 1 , but was significantly reduced (by about $25 \%-30 \%$ ) on day 9 . This is likely because of the $25 \%$ reduction in serum SHBG observed with the administration of oral testosterone after 9 days. The reduction in SHBG may decrease the serum total estradiol concentration, without affecting the free estradiol concentration, as was observed for the calculated free testosterone (Figure [D]). Nevertheless, future studies of oral testosterone therapy in hypogonadal men should follow serum estradiol concentrations, as well as estrogen-responsive endpoints such as bone density, to ensure that the reduction in serum estradiol does not have adverse effects on men being treated with this therapy.

The effect of food on the absorption of this formulation is uncertain; however, prior work in this area has not shown a significant effect of food on absorption of nonesterified oral testosterone (Amory et al, 2006). The macronutrient composition of food intake has a dramatic effect on the absorption of esterified (and therefore highly lipophilic) formulations of oral testosterone, such as oral testosterone undecanoate, for which absorption is dependent on concurrent ingestion of a fatty meal and is minimal in the fasting state (Bagchus et al, 2003; Schnabel et al, 2007). Additional testing of modified slow-release oral testosterone with and without food will be needed before the effect of food on the absorption of this formulation will be understood. Additionally, the need for dosing the formulation 3 times daily is a drawback. However, if the oral testosterone can be effectively administered at mealtimes, this may improve compliance.

This formulation of oral testosterone was well tolerated and free of reported gastrointestinal side effects. Moreover, it is important to note that there were no significant alterations in liver or kidney function in this study requiring discontinuation of the study drug, albeit over a relatively short period of time. The sole instance of elevated liver enzymes observed in this study was attributed to an evening of heavy drinking and resolved despite continued administration of the oral testosterone. The observation that formulations of nonalkylated oral testosterone are not associated with liver toxicity is consistent with prior reports using oral testosterone for the treatment of hypogonadism for extended periods of time without liver inflammation (Johnsen et al, 1974; Johnsen, 1978; Amory et al, 2011). Indeed, we are unaware of any instance of liver toxicity from the administration of nonalkylated forms of oral testosterone. Nevertheless, future studies of oral testosterone will be needed to determine the long-term effect of oral testosterone therapy on the liver. Other adverse events were due to the profound hypogonadism induced by the acyline and reversed with time. 
In summary, our data suggests that modified, slowrelease oral testosterone may be a useful therapy for the treatment of testosterone deficiency. This formulation will be the focus of future studies investigating its safety and efficacy for androgen replacement therapy in men with hypogonadism.

\section{Acknowledgments}

The authors thank Ms Marilyn Busher, Ms Kathy Winter, Ms Iris Nielsen, Ms Kathryn Torrez Duncan, Ms Constance Pete, Ms Dorothy McGuinness, and Mr Robert Bale for assistance with the clinical aspects of this study, and David $\mathrm{W}$. Amory $\mathrm{MD}, \mathrm{PhD}$, for critical review of the manuscript.

This work was supported by the Eunice Kennedy Shriver National Institute of Child Health and Human Development, a division of the National Institutes of Health through cooperative agreement U54 HD42454 as part of the Cooperative Contraceptive Research Centers Program and GlaxoSmithKline. A portion of this work was conducted through the Clinical Research Center facility at the University of Washington and supported by NIH grant UL1-RR-025014.

\section{References}

Amory JK, Bremner WJ. Oral testosterone in oil plus dutasteride: a pharmacokinetic study in men. J Clin Endocrinol Metab. 2005; 90:2610-2617. [PubMed: 15713724]

Amory JK, Bush MA, Zhi H, Caricofe RB, Matsumoto AM, Wang C, Swerdloff RS, Clark RV. Oral testosterone with and without concomitant inhibition of 5a-reductase by dutasteride in hypogonadal men for 28 days: pharmacokinetics, pharmacodynamics and safety. J Urol. 2011; 185:626-632. [PubMed: 21168874]

Amory JK, Page ST, Bremner WJ. Oral testosterone in oil: pharmacokinetic effects of 5a-reduction with finasteride or dutasteride and food intake in men. J Androl. 2006; 27:72-78. [PubMed: 16400081]

Andriole GL, Bostwick DG, Brawley OW, Gomella LG, Marberger M, Montorsi F, Pettaway CA, Tammela TL, Teloken C, Tindall DJ, Somerville MC, Wilson TH, Fowler IL, Rittmaster RS. REDUCE study group. Effect of dutasteride on the risk of prostate cancer. N Engl J Med. 2010; 362:1192-1202. [PubMed: 20357281]

Araujo AB, Esche GR, Kupelian V, O’Donnell AB, Travison TG, Williams RE, Clark RV, McKinlay JB. Prevalence of symptomatic androgen deficiency in men. J Clin Endocrinol Metab. 2007; 92:4241-4247. [PubMed: 17698901]

Bagchus WM, Hust R, Maris F, Schnabel PG, Houwing NS. Important effect of food on the bioavailability of oral testosterone undecanoate. Pharmacotherapy. 2003; 23:319-325. [PubMed: 12627930]

Brachet C, Vermeulen J, Heinrichs C. Children's virilization and the use of a testosterone gel by their fathers. Eur J Pediatr. 2005; 164:646-647. [PubMed: 16025298]

Daggett PR, Wheeler MJ, Nabarro JD. Oral testosterone, a reappraisal. Horm Res. 1978; 9:121-129. [PubMed: 640576]

de Ronde W. Hyperandrogenism after transfer of topical testosterone gel: case report and review of published and unpublished studies. Hum Reprod. 2009; 24:425-428. [PubMed: 18948313]

Dobs AS, Meikle AW, Arver S, Sanders SW, Caramelli KE, Mazer MA. Pharmacokinetics, efficacy and safety of a permeation-enhanced testosterone transdermal system in comparison with biweekly injections of testosterone enanthate for the treatment of hypogonadal men. J Clin Endocrinol Metab. 1999; 84:3469-3478. [PubMed: 10522982]

Foss GL. Clinical administration of androgens. Lancet. 1939; 1:502-504.

Fossa SD, Opjordsmoen S, Haug E. Androgen replacement and quality of life in patients treated for bilateral testicular cancer. Eur J Cancer. 1999; 35:1220-1225. [PubMed: 10615233]

Franchimont P, Kicovic PM, Mattei A, Roulier R. Effects of oral testosterone undecanoate in hypogonadal male patients. Clin Endocrinol (Oxf). 1978; 9:313-320. [PubMed: 102469] 
Gann PH, Hennekens CH, Longcope C, Stampfer MJ. Prospective study of sex hormone levels and risk of prostate cancer. J Natl Cancer Inst (Bethesda). 1996; 88:1118-1126.

Gill JK, Wilkens LR, Pollak MN, Stanczyk FZ, Kolonel LN. Androgens, growth factors, and risk of prostate cancer: the multiethnic cohort. Prostate. 2010; 70:906-915. [PubMed: 20166103]

Gooren LJ. A ten-year safety study of the oral androgen testosterone undecanoate. J Androl. 1994; 15:212-215. [PubMed: 7928661]

Herbst KL, Coviello AD, Page ST, Amory JK, Anawalt BD, Bremner WJ. A single dose of the potent gonadotropin-releasing hormone antagonist acyline suppresses gonadotropins and testosterone for 2 weeks in healthy young men. J Clin Endocrinol Metab. 2004; 89:5959-5965. [PubMed: 15579744]

Idan A, Griffiths KA, Harwood DT, Seibel MJ, Turner L, Conway AJ, Handlesman DJ. Long-term effects of dihydrotestosterone treatment on prostate growth in healthy, middle-aged men without prostate disease: a randomized, placebo-controlled trial. Ann Intern Med. 2010; 153:621-632. [PubMed: 21079217]

Johnsen SG. Long-term oral testosterone and liver function. Lancet. 1978; 1(8054):50. [PubMed: 74534]

Johnsen SG, Bennett EP, Jensen VG. Therapeutic effectiveness of oral testosterone. Lancet. 1974; 2(7895):1473-1475. [PubMed: 4140393]

Katznelson L, Finkelstein JS, Schoenfeld DA, Rosenthal DI, Anderson EJ, Klibanski A. Increase in bone density and lean body mass during testosterone administration in men with acquired hypogonadism. J Clin Endocrinol Metab. 1996; 81:4358-4365. [PubMed: 8954042]

Lowdell CP, Murray-Lyon IM. Reversal of liver damage due to long term methyltestosterone and safety of 17-alpha alkylated androgens. Br Med J. 1985; 291:637-645. [PubMed: 3928062]

Nieschlag E, Mauss J, Coert A, Kicovic P. Plasma androgen levels in men after oral administration of testosterone and testosterone undecanoate. Acta Endocrinol (Copenh). 1975; 79:366-374. [PubMed: 1173495]

Page ST, Bremner WJ, Clark RV, Bush MA, Zhi H, Caricofe RB, Smith PM, Amory JK. Nanomilled oral testosterone plus dutasteride effectively normalizes serum testosterone in normal men with induced hypogonadism. J Androl. 2008; 29:222-227. [PubMed: 18077826]

Page ST, Lin DW, Mostahel EA, Marck BT, Wright JL, Wu J, Amory JK, Nelson PS, Matsumoto AM. Dihydrotestosterone administration does not increase intraprostatic androgen concentrations or alter prostate androgen action in healthy men: a randomized-controlled trial. J Clin Endocrinol Metab. 2011; 96:430-437. [PubMed: 21177791]

Pavlatos AM, Fultz O, Monberg MJ, Vootkur A. Review of oxymetholone: a 17alpha-alkylated anabolic-androgenic steroid. Clin Ther. 2001; 23:789-801. [PubMed: 11440282]

Roth MY, Dudley RE, Hull L, Leung A, Christenson P, Wang C, Swerdloff R, Amory JK. Steady-state pharmacokinetics of oral testosterone undecanoate with concomitant inhibition of 5a-reductase by finasteride. Int J Androl. 2011; 34:541-547. [PubMed: 20969601]

Schnabel PG, Bagchus W, Lass H, Thomsen T, Geurts TB. The effect of food composition on serum testosterone levels after oral administration of Andriol Testocaps. Clin Endocrinol (Oxf). 2007; 66:579-585. [PubMed: 17371478]

Snyder CN, Clark RV, Caricofe RB, Bush MA, Roth MY, Page ST, Bremner WJ, Amory JK. Pharmacokinetics of 2 novel formulations of modified-release oral testosterone alone and with finasteride in normal men with experimental hypogonadism. J Androl. 2010; 31:527-535. [PubMed: 20378927]

Snyder PJ, Peachey H, Berlin JA, Hannoush P, Haddad G, Dlewati A, Santanna J, Loh L, Lenrow DA, Holmes JH, Kapoor SC, Atkinson LE, Strom BL. Effects of testosterone replacement in hypogonadal men. J Clin Endocrinol Metab. 2000; 85:2670-2677. [PubMed: 10946864]

Swerdloff RS, Wang C, Cunningham G, Dobs A, Iranmanesh A, Matsumoto AM, Snyder PJ, Weber T, Longstreth J, Berman N. Long-term pharmacokinetics of transdermal testosterone gel in hypogonadal men. J Clin Endocrinol Metab. 2000; 85:4500-4510. [PubMed: 11134099]

Thompson IM, Goodman PJ, Tangen CM, Lucia MS, Miller GJ, Ford LG, Lieber MM, Cespedes RD, Atkins JN, Lippman SM, Carlin SM, Ryan A, Szczepanek CM, Crowley JJ, Coltman CA Jr. The 
influence of finasteride on the development of prostate cancer. New Eng J Med. 2003; 349:215224. [PubMed: 12824459]

Turani H, Levi J, Zevin D, Kessler E. Hepatic lesions in patients on anabolic androgenic therapy. Isr J Med Sci. 1983; 19:332-337. [PubMed: 6853130]

US Food and Drug Administration. Silver Spring, MD: US FDA; 2009 May 7. Testosterone Gel Safety Concerns Prompt FDA to Require Label Changes, Medication Guide [FDA news release]. Available at:http://www.fda.gov/NewsEvents/Newsroom/PressAnnouncements/2009/ ucm149580.htm. [Accessed May 2011]

Vermeulen A, Verdonck L, Kaufman JM. A critical evaluation of simple methods for the estimation of free testosterone in serum. J Clin Endocrinol Metab. 1999; 84:3666-3672. [PubMed: 10523012]

Wang C, Alexander G, Berman N, Salehian B, Davidson T, McDonald V, Steiner B, Hull L, Callegari C, Swerdloff RS. Testosterone replacement therapy improves mood in hypogonadal men-a clinical research center study. J Clin Endocrinol Metab. 1996; 81:3578-3583. [PubMed: 8855804]

Wang C, Swerdloff RS, Iranmanesh A, Dobs A, Snyder PJ, Cunningham G, Matsumoto AM, Weber T, Berman N. Testosterone Gel Study Group. Transdermal testosterone gel improves sexual function, mood, muscle strength, and body composition parameters in hypogonadal men. J Clin Endocrinol Metab. 2000; 85:2839-2853. [PubMed: 10946892]

Westaby D, Ogle SJ, Paradinas FJ, Randell JB, Murray-Lyon IM. Liver damage from long-term methyltestosterone. Lancet. 1977; 2:262-263. [PubMed: 69876]

Winters SJ, Wang C. LH and non-SHBG testosterone and estradiol levels during testosterone replacement of hypogonadal men: further evidence that steroid negative feedback increases as men grow older. J Androl. 2010; 31:281-287. [PubMed: 19959827]

Zhang GY, Gu YQ, Wang XH, Cui YG, Bremner WJ. A pharmacokinetic study of injectable testosterone undecanoate in hypogonadal men. J Androl. 1998; 19:761-768. [PubMed: 9876028] 

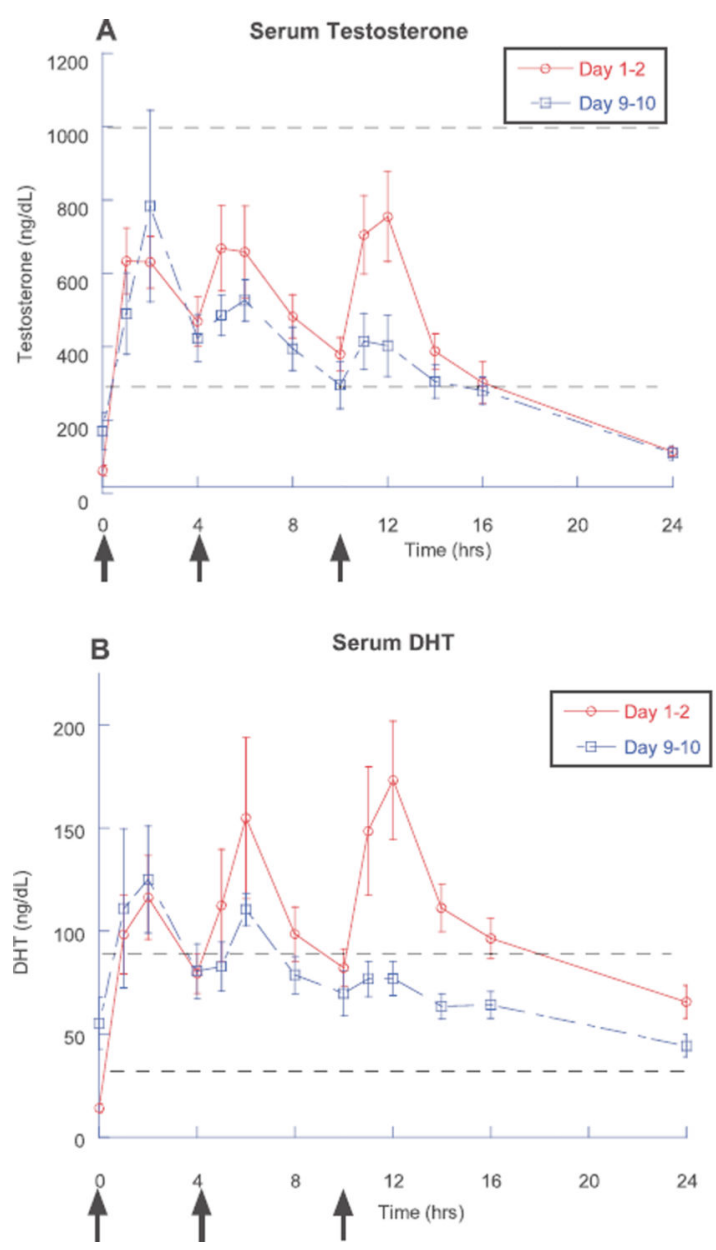
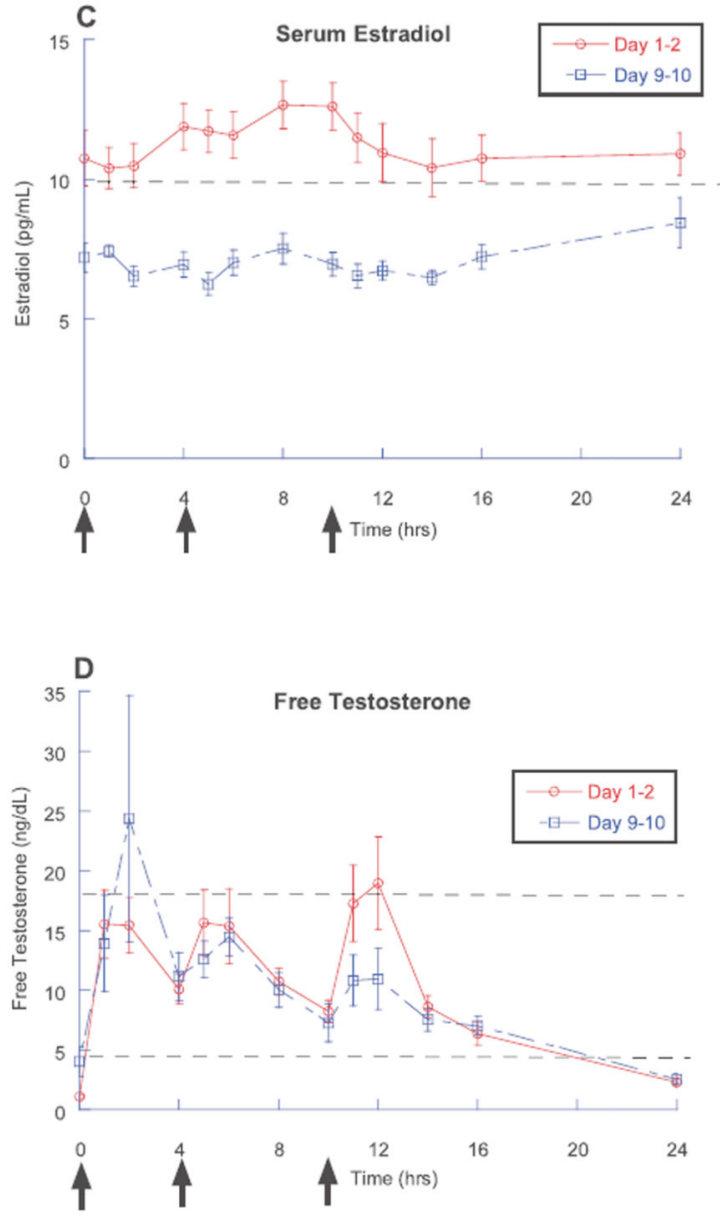

Figure.

Mean $( \pm$ SEM) total testosterone $(\mathbf{A})$, dihydrotestosterone (DHT) $(\mathbf{B})$, estradiol $(\mathbf{C})$, and calculated free testosterone (D) in men with experimental hypogonadism treated with 300 mg of modified, slow-release oral testosterone 3 times daily on day 1-2 (red) and day 9-10 (blue). Testosterone was dosed at time 0 and 4 and 10 hours later (arrowheads). Dotted lines represent the upper and lower limit of the reference range for each hormone. 


\section{Table 1}

Screening characteristics of study subjects $(n=12)$

\begin{tabular}{lc}
\hline Characteristic & Mean \pm SD (Range) \\
\hline Age, yr & $28.1(19-51)$ \\
Body weight, kg & $79.9 \pm 7.5$ \\
BMI, kg/m² & $24.2 \pm 1.5$ \\
FSH, IU/L & $3.2 \pm 1.5$ \\
LH, IU/L & $5.4 \pm 4.4$ \\
Testosterone, ng/dL & $510 \pm 13$ \\
PSA, ng/mL & $0.91 \pm 0.56$ \\
\hline
\end{tabular}

Abbreviations: BMI, body mass index; FSH, follicle-stimulating hormone; LH, luteinizing hormone; PSA, prostate-specific antigen. 


\section{Table 2}

Mean and maximum hormone concentrations on day 1 and day 9 of treatment with $300 \mathrm{mg}$ of oral testosterone 3 times daily for 9 days

\begin{tabular}{|c|c|c|c|}
\hline & Variable & Day & Geometric Mean (\% CV) \\
\hline \multirow[t]{4}{*}{ Testosterone (reference range, $300-1000 \mathrm{ng} / \mathrm{dL}$} & Maximum concentration & $1-2$ & $924(44 \%)$ \\
\hline & & $9-10$ & $741(71 \%)^{a}$ \\
\hline & Mean concentration & $1-2$ & $378(45 \%)$ \\
\hline & & $9-10$ & $315(41 \%)^{b}$ \\
\hline \multirow[t]{4}{*}{ DHT (reference range, $30-90 \mathrm{ng} / \mathrm{dL}$ ) } & Maximum concentration & $1-2$ & $233(49 \%)$ \\
\hline & & $9-10$ & $142(55 \%)^{a}$ \\
\hline & Mean concentration & $1-2$ & $96(38 \%)$ \\
\hline & & $9-10$ & $69(41 \%)^{a}$ \\
\hline \multirow[t]{4}{*}{ SHBG (reference range, $3-57 \mathrm{nmol} / \mathrm{L}$ ) } & Maximum concentration & $1-2$ & $31(48 \%)$ \\
\hline & & $9-10$ & $22(48 \%)$ \\
\hline & Mean concentration & $1-2$ & $27(46 \%)$ \\
\hline & & $9-10$ & $19(47 \%)^{a}$ \\
\hline \multirow[t]{4}{*}{ Estradiol (reference range, $10-60 \mathrm{pg} / \mathrm{mL}$ ) } & Maximum concentration & $1-2$ & $14(28 \%)$ \\
\hline & & $9-10$ & $9(27 \%)$ \\
\hline & Mean concentration & $1-2$ & $11(18 \%)$ \\
\hline & & $9-10$ & $7(18 \%)^{a}$ \\
\hline \multirow[t]{4}{*}{ Free $\mathrm{T}$ (reference range, $4.7-18 \mathrm{ng} / \mathrm{dL}$ ) } & Maximum concentration & $1-2$ & $24(47 \%)$ \\
\hline & & $9-10$ & $21(86 \%)$ \\
\hline & Mean concentration & $1-2$ & $8.7(43 \%)$ \\
\hline & & $9-10$ & $8.3(37 \%)$ \\
\hline
\end{tabular}

Abbreviations: CV, coefficient of variation; DHT, dihydrotestosterone; SHBG, sex hormone-binding globulin; T, testosterone.

$a_{P<.05 \text { compared with day } 1-2 .}$

${ }^{b} P<.1$ compared with day $1-2$. 